\title{
Not by Imaginings Alone: On How Imaginary Worlds Are Established
}

\begin{abstract}
This article explores the relation between belief-like imaginings and the establishment of imaginary worlds (often called fictional worlds). After outlining the various assumptions my argument is premised on, I argue that belief-like imaginings, in themselves, do not render their content true in the imaginary world to which they pertain. I show that this claim applies not only to imaginative projects in which we are instructed or intend to imagine certain propositions, but also to spontaneous imaginative projects. After arguing that, like guided imaginative projects, spontaneous projects involve specific imaginary truths, I conclude that imaginative projects, whether spontaneous or deliberate, comprise not only imaginings, but also mental acts of determining such truths.
\end{abstract}

KEYWORDS: belief-like imagining, imaginary worlds, imaginary truths, fiction, spontaneous imaginings

\section{Introduction}

It is commonly accepted that an imaginative project-the overall mental activity we engage in when we imagine-encompasses, in addition to belief-like imaginings, other kinds of mental states, such as emotional reactions, conative states, mental imagery, motivations. (See, for example, Currie and Ravenscroft 2002; Doggett and Egan 20I2; Gendler 2003; Ichino 20I9; Kind 2013, 2016; Langland-Hassan 20I2; Liao and Doggett 20I4; Liao and Gendler 20I9; Nichols 2004; Nichols and Stich 2003; Schellenberg 2013; Walton I990, 20I5). For instance, one might find oneself imagining that one is participating in an anticorruption demonstration, that the demonstration is taking place at a downtown plaza, and related propositions. In addition to these belief-like imaginings, the imaginative project might involve mental images of signs and chants, desire-like states, such as the wish that the demonstration proves efficacious, and so on. Similarly, someone pretending that the next-door neighbor is an evil dragon not only imagines, when she sees the neighbor approaching, that a dragon is approaching, but might also have a fear-like emotion, be motivated to escape, wish that the dragon would disappear. Such mental responses routinely ensue not only in the course of spontaneously imagining, but also in engaging with works of fiction, games of make-believe, and other contexts in which belief-like imaginings arise. Despite ongoing debate over the nature of these states, it is widely accepted that they are integral to imaginative projects. Indeed, it is partly due to these states that 
belief-like imaginings are deemed belief-like: belief-like imaginings are akin to beliefs in that they are functionally related to these states just as beliefs are related to these states (or to similar ones).

Yet another element of an imaginative project is what we often refer to as its imaginary or fictional world (and likewise, its imaginary or fictional truths). Asked about the world of her project, the first of the aforementioned imaginers would probably respond that an anti-corruption demonstration took place in that world; asked the same question, the second would describe the said world as one in which an evil dragon lived next door. In general, whether we intend to imagine or simply find ourselves imagining, and whether the context of our imagining is playing a game of make-believe, daydreaming, reading a novel, or something else, we can speak of the world of our imaginative project, and about facts or truths of that world.

In what follows, I examine the relation between imaginings and the determination of these worlds and their facts. First, I argue that imagining a proposition (in the belief-like sense) does not render the proposition true in the pertinent imaginary world (section I). Second, I show that this claim applies, specifically, to spontaneous imaginative projects (subsection 2.I). Third, I propose two explanations of the establishment of imaginary worlds in spontaneous projects, and I argue that one of them is more plausible than the other (subsections 2.2 and 2.3). I conclude that in addition to belief-like imaginings and the various sorts of mental states that typically accompany belief-like imaginings, imaginative projects - particularly spontaneous projects-encompass mental acts of determining imaginary truths.

Two preliminary comments are in order. First, my argument is not committed to any specific metaphysics of imaginary or fictional worlds or entities; for convenience, I take such worlds to be sets of propositions. More specifically, I adopt Kendall Walton's characterization of fictional worlds, which identifies them with 'sets of propositions-as-indicated-by-a-given-work (or game of make-believe or . . . daydream)' (Walton I990: 67). On this characterization, two imaginary or fictional worlds can comprise the same set of propositions yet differ because they are set forth in different imaginative projects, namely, projects involving different, and differently related, sorts of mental states (that is, imaginings, emotional responses, conative states, and the like).

Second, although the terms fictional world and fictional truths are often used to refer to the world and truths associated with imagining in general, I use these terms solely to refer to the world and truths that are assumed by a work of fiction. That is, I use the terms fictional world and fictional truths to refer only to the propositions that a given work of fiction assumes to be true, whereas I refer to the world and truths associated with an imaginer's mental activity-her imaginative project-as the project's imaginary world and imaginary truths (or $i$-world, $i$-truths, and, likewise, $i$-falsehoods).

My rationale for this distinction is that there is a difference between the world or truths that are assumed by a work of fiction, and the world or truths that are set down by the imaginer as part of her imaginative mental activity, activity that can arise either in response to a work of fiction, or otherwise (such as in daydreaming or 
impromptu imagining.). Even if it is usually the case that when we engage with a work of fiction and recognize which propositions it takes to be true, we respond by taking those fictional truths to be the i-truths of our imaginative project, the two sets of propositions-the fictional truths and the project's i-truths-are defined, and recognized, differently. In particular, to find out which propositions a work of fiction assumes to be true, we need to interpret the work (just as we need to interpret works of history, biographies, or newspaper articles to find out which propositions they assume to be true). By contrast, to uncover $i$-truths, we need to scrutinize the imaginer's mental activity. Whatever the techniques used to interpret a work of fiction and find out what is true in the work, discovering what has been set down as true in the course of one's imaginative activity requires reflection on that activity.

\section{Imaginings and Imaginary Truths}

Suppose you are imagining a proposition, for example, that a certain building is about to explode, that the price of corn is dropping, or that Hillary Clinton is the current US president. Reflecting on your imaginative project, you can recountgenerally, correctly-what you imagined. Suppose, however, that you are asked whether the proposition you imagined was true in the world of your imaginative project. This question, without further qualification, might strike you as odd, probably because you take the answer to be trivial: it is obvious, you assume, that the proposition you imagined was i-true. After all, you imagined it to be true. Imagining that $p$, you assume, renders $p$ true in the imaginative project's i-world.

In this section, I show that this view is mistaken: imagining a proposition does not render it i-true. I do not deny that to imagine a proposition is to imagine it to be true (that is, true in the pertinent $\mathrm{i}$-world). My claim is that it does not follow from this that the imagined proposition is true in the pertinent i-world. Compare: to believe a proposition is to believe it to be true (that is, true simpliciter, in the real world), but believing a proposition does not render the believed proposition true. That is, imaginings, like beliefs, lack the power to render their content true in the relevant sense. Of course, comparing imaginings and beliefs in this respect is only a clarification of the thesis I seek to defend, not an argument for it. To defend the thesis, I adduce cases where imaginings do not have i-true content. I argue that, since we can imagine propositions that are not true in the pertinent i-world, imagining does not, in general, render its content i-true. (Note that there is a sense in which the content of imaginings is ipso facto true-in-a-world-a sense in which the content of beliefs too is ipso facto true-in-a-world. In analyzing the semantics of belief, we say that if one believes that Hillary Clinton is the current US president, then in the belief-world of that belief, Clinton is the current president. More precisely, the belief's content is specified by the set of possible worlds in which the believed proposition is true. Similarly, an imagined content can be specified by the set of possible worlds in which the imagined proposition is true. My claim, however, does not pertain to the semantics of content, but rather to the sense in which imagining can be correct or incorrect. Whatever the sense in which correctness applies to imaginings, this sort of correctness is evaluated in terms of 
the world at which imaginings are directed as per the characterization I present above in the introduction. See also Chasid [forthcoming] and Chasid [2020].)

Consider imaginings that arise in response to reading fiction. In reading a novel, for instance, we can initially imagine, as per allusions in the novel's early chapters, that $\mathrm{A}$ is the villain; when we reach the final chapter, having followed all the novel's twists and turns, we imagine that B, not A, is the villain. Likewise, we might first imagine that, as another work indicates, a certain building is going to explode, and then, in line with that work's subsequent guidance, that the building is not going to explode. Such cases involve a shift from imagining a certain proposition to imagining a proposition overtly inconsistent with it. Hence, at least one of the imagined propositions - presumably the first-is i-false: the fact that we imagine it does not render it i-true. Generalizing from the way imaginings function in such cases, it can be concluded that imaginings do not render their content i-true: imaginings are structured in such a way that their content can be either i-true or i-false.

Several objections to this argument come to mind. First, it might be argued, as per the said distinction between fictional worlds and $\mathrm{i}$-worlds, that although we imagine the fictional falsehood that $\mathrm{A}$ is the villain or that the building is going to explode, this proposition is nonetheless $i$-true. That is, even if certain propositions are false in the work's fictional world, in the i-world-the world of the imaginative project that ensues in response to that work-these propositions are true. Those who take this position maintain that in general, regardless of what a work of fiction assumes to be true, if we imagine a proposition in response to that work, the imagined proposition is ipso facto rendered true in the i-world of our project.

This objection is problematic. One problem pertains to what the imaginer would report if asked about her imaginative project. Presumably, she will say that in imagining that A was the villain, she imagined an i-falsehood: she will describe the i-world of her imaginative project as being more or less the same as the work's fictional world. For it seems that when we engage with fiction, our imaginative activity complies with the work's mandate, and specifically, sets down that the propositions assumed by the work to be true (that is, the fictional truths) are also i-truths. Of course, we do not always know, in reading the work, whether what we are imagining is fictionally true or false, and we do not immediately deem specific propositions to be i-true. Rather, we imagine what the work recounts, and are aware that what we are imagining is either i-true or i-false. We direct our imaginings at a certain $\mathrm{i}$-world, without setting down that the propositions we imagine are i-true. Our awareness that the propositions we imagine are putatively assessed for i-truth indicates, I contend, that they are not rendered i-true solely by virtue of being imagined.

Moreover, if imaginings rendered their content $\mathrm{i}$-true, then shifting between imaginings with incompatible content would entail shifting from one i-world to another, or to put it differently, revising the pertinent i-world. Granted, revision of an i-world sometimes occurs. Interpreting a work incorrectly, for instance, we might initially assume that the unfolding events occur in London England, but upon interpreting the work correctly, realize that the events are described as occurring in London Ontario; we respond by revising the i-world accordingly. 
Such revisions, however, do not reflect the shifts from one imagining to another that are exemplified by the villain and soon-to-explode building cases. Examining our reactions to such shifts clarifies this point. As noted in the introduction, belief-like imaginings are often accompanied by emotional, cognitive, and conative reactions that resemble our reactions to the corresponding beliefs. For instance, when we shift from imagining that $\mathrm{A}$ is the villain to imagining that $\mathrm{B}$ is the villain, we might have discovery- and surprise-like feelings: we might regret that $\mathrm{A}$ was unjustly accused, be relieved that he is no longer under suspicion, have empathy for A's family, and the like. Similarly, upon shifting to imagining that the building is not going to explode, we feel relieved, happy that it was a false alarm.

Such reactions would not arise if the said shifts from one imagining to another entailed shifting from one i-world to another. For what could be surprising about imagining that A remains the villain in the i-world set down initially, whereas B is the villain in a different i-world? And why do we feel regret about A's having been unjustly accused, if it remains the case that $\mathrm{A}$ is the villain in the initially posited i-world? In short, if our imaginings pertain to two different $\mathrm{i}$-worlds, one in which $\mathrm{A}$ is the villain, and another in which B is the villain, our emotional, conative, and cognitive reactions are inexplicable. Similarly, upon shifting to imagining that in another i-world, the building is not going to explode, why would we feel relieved? After all, it is still true in the initially posited i-world that the building is going to explode. Our reactions to such shifts only make sense if these shifts are intraworld shifts, that is, if our imaginings are directed at the same i-world. In other words, such shifts are shifts from imagining falsehoods to imagining truths (or vice versa) in a specific i-world, as is the case when we shift between beliefs about real-world events.

The manner in which our imaginings unfold also attests that in each of the cases in question, our imaginings are directed at a single i-world, and the said shifts are shifts from imagining a falsehood to imagining a truth in that i-world. In reading, and thereupon imagining, say, that A was abroad when the crimes ascribed to A were perpetrated, we are led to imagine that $\mathrm{A}$ is not the villain. That is, we understand that, for the inference that $\mathrm{A}$ is the villain to be valid, it cannot be true, in the specific $i$-world in question, that A was abroad when the crimes occurred. Upon being informed that A was abroad when the crimes occurred, we conclude that A is not the villain, and our imaginings shift accordingly. Our learning, and thereupon imagining, that $\mathrm{A}$ is not the villain, presupposes that the relevant propositions are assessed for truth in the same i-world. The same reasoning applies to the case of the building, and to similar shifts from imagining one proposition to imagining an overtly inconsistent proposition: the manner in which our imaginings unfold presupposes that the incompatible propositions are assessed for truth in the same i-world.

A similar objection might claim that while a shift between incompatible imaginings does not entail a shift between $\mathrm{i}$-worlds, it entails that the i-world in question is inconsistent. My arguments refute this objection as well. That is, even if projects in which the i-world is inconsistent are possible, in such projects, the imaginer's reactions to the shift in her imaginings, and so, too, the way in which her imaginings unfold, her retrospective accounts of the project, and so on, do not 
mesh with the claim that the incompatible propositions she imagines are all true in the same i-world. For the putative response to imagining an inconsistent i-world would be a sense of bewilderment or incomprehension, whereas the reactions that typically ensue are not bafflement and incomprehension, but rather sorrow, regret, relief, and the like.

Imaginings with i-false content arise not only in response to works of fiction, but also in other contexts. Consider the well-known example devised by Walton (I990: 37): Eric and Gregory play a game of make-believe in which they take tree stumps to be bears. Playing this game, they engage in an imaginative project in which some $\mathrm{i}$-truths are determined by the stumps-are-bears rule. These i-truths have the form there is a bear at such-and-such a spot, the spots in question being spots where there is a real-world tree stump. As Walton presents the scenario, Eric and Gregory falsely believe that there is a tree stump at a certain spot, and imagine that there is a bear at that spot. That is, they imagine an i-falsehood. Indeed, when they approach the spot and discover that there is no stump there, they realize that they imagined an i-falsehood; they proceed to imagine the i-truth that there is no bear at that spot, and they respond to the shift by feeling relieved.

To explain this case, we must grant that belief-like imaginings do not render their content i-true. Of course, upon discovering that there is no stump at the said spot, Eric and Gregory could decide to revise their game's i-world and make the proposition that there is a bear at that spot i-true. Were they to do so, their reactions would be different: no relief-like feeling would arise, and they might attempt to fight the bear, escape, or whisper to avoid waking the bear. The important point is that they can stick to the stumps-are-bears rule, direct all their imaginings at a single i-world, and recognize that they imagined an i-falsehood.

A different objection might concede that occasionally, belief-like imaginings do not render their content $\mathrm{i}$-true, but argue that the cases I have adduced are too unusual to warrant the generalization that belief-like imaginings never render their content i-true. I maintain, however, that generalizing from the adduced cases to the conclusion that imaginings do not render their content i-true is not problematic. Though I believe that cases akin to those I have adduced are commonplace, even were they rare (as the objection assumes), they would merit being taken into consideration in theorizing about imagination. These cases can play a role comparable to that played by the case of hallucination in theorizing about perception, or the possibility of brains in a vat in theorizing about mental content. Despite being far from common, to say the least, the hallucination and brains-in-a-vat examples play a key role in defending seminal theories about perceptual experience or mental content.

The question, in short, is whether belief-like imagining in itself renders its content i-true. The foregoing arguments offer a cogent rationale for the thesis that it does not, since imaginings can, and often do, have i-false content. In addition to these arguments, the overall similarity between belief-like imaginings and beliefs provides a meta-theoretical motivation for this thesis. We often believe propositions to be true, and ordinarily, many of our beliefs are true. But since we sometimes have false beliefs, belief in and of itself cannot render its content true. Similarly, we imagine propositions to be true in the pertinent i-world, and 
ordinarily, many of our imaginings have i-true content. Yet as the foregoing arguments showed, since we sometimes imagine i-falsehoods, the attitude of belief-like imagining cannot in and of itself render its content i-true.

A variant of this objection might claim that the foregoing arguments only show that imaginings do not render their content i-true in the specific type of cases I have adduced, namely, cases where an external source stipulates i-truths (for example, what a fictional work assumes to be true, a game's rules, and so on). However, in cases where there is no such external criterion-so it might be argued -imaginings can indeed render their content i-true, or at any rate, it has not been shown that they do not. I address this objection in the next section.

\section{Extending the Argument}

\section{I Spontaneous Imaginative Projects}

The imaginative projects discussed above arise in response to directives. In such mandated projects, we acquire beliefs regarding how the imaginative project should unfold, then engage with the project accordingly. The examples we examined show that engaging in such projects involves being directed to imagine various propositions, and in addition, being directed to take certain propositions to be i-true. Imaginative projects can also be guided, not by instructions, but by the imaginer's own intentions: we sometimes plan to imagine certain propositions. In such cases, too, to the extent that i-truths are determined, they seem to be determined by virtue of our intention to imagine that which is i-true, not by our imaginings themselves. Indeed, just as we can intend to imagine i-truths, we can also intend to imagine i-falsehoods. If, for example, we want to imagine certain scenarios from the perspective of someone who has been fooled into believing that these scenarios are facts of the i-world, we stipulate that certain propositions are i-false and imagine them.

I call imaginative projects (or parts thereof) and imaginings that ensue in response to instructions, or are intended, guided imaginative projects and guided imaginings respectively. Thus far I have shown that guided imaginings do not render their content i-true. The question is now whether unguided, that is, spontaneous, belief-like imaginings render their content i-true.

For one thing, to claim that unguided imaginings, in contrast to guided imaginings, render their content i-true, seems problematic. Given that spontaneous and guided imaginings are attitudes of the very same type, and differ only with respect to whether they arise deliberately or not, how can unguided imaginings, simply because they arise extemporaneously, render their content i-true? The burden of proof seems to fall on those who distinguish, apropos the determination of i-truths, between guided and unguided imaginings.

Moreover, the same arguments that I raise against the claim that guided imaginings render their content i-true also apply to unguided imaginings. Consider unguided projects that involve shifts from imagining a proposition to imagining a contrary proposition. You might find yourself imagining, say, that a certain building is going to explode, that a search turns up no explosives, and 
hence (so you proceed to imagine) that it is not going to explode. You might likewise find yourself imagining that there is a gold nugget in a certain river, and then that the sun sets, revealing that the shiny object is not gold but a pebble illuminated by the sun. In such unguided projects, it is utterly implausible that all the imagined propositions are i-true, and that in shifting from imagining one proposition to imagining the contrary proposition, you also shifted from implicitly invoking one i-world to implicitly invoking another. For were you to shift from invoking one world to invoking another, your cognitive, conative, and emotional reactions would be different. If, for example., in one i-world the building's explosion is still imminent, but in another i-world it was never imminent, you would not feel relief; if the shiny object is indeed a gold nugget in the first i-world, you would not feel, for example, surprised or disappointed that it is a pebble in the other i-world. We must therefore conclude that, in these unguided projects, one's imaginings pertain to the same i-world throughout.

Furthermore, the unfolding of these unguided projects only makes sense if the imaginings are directed at the same i-world. After imagining that a certain building is going to explode, or that there is a gold nugget in the river, imagining that a sweep of the building uncovers no explosives or that the sun is setting and its illumination of the river has changed would hardly induce you to imagine that in a different $\mathrm{i}$-world the building is not going to explode or that in a different $\mathrm{i}$-world the shiny object is not gold. Rather, they would induce you to imagine that, in one and the same i-world-the i-world at which your first imaginings were directed-the building is not, in fact, going to explode, or that the shiny object is not gold. Realizing that it is highly unlikely to be the case that no explosives are found in the building but it is about to explode, you change your imaginings accordingly. Likewise, realizing that, with the changed illumination, the object no longer resembles a gold nugget, you imagine that it is not a gold nugget as you first imagined it to be. In general, the fact that your imaginings are directed at a single i-world throughout - that is, the propositions you imagine are assessed for truth in the same i-world-makes it possible to account for the manner in which such shifts occur.

Lastly, if asked about the unfolding of an unguided project of the sort we are discussing, the imaginer is likely to be completely baffled by the suggestion that her imaginings were directed at two different i-worlds. The fact that, in unguided projects, the imaginer lacks real-time awareness of how her project unfolds, and can describe it only upon retrospective reflection, ensues because such projects unfold without the mediation of beliefs or intentions about how they should unfold. I obviously do not deny that we can err in reporting on our imaginative activities. As Eric Schwitzgebel (20II) famously demonstrated, discerning our own mental activity is problematic in general, not only vis-à-vis imagining. But there seems to be no reason to say that an imaginer must be mistaken in reporting that all her imaginings pertained to the same i-world.

In short, since it is possible to suddenly find oneself imagining propositions that are not i-true, it follows that having spontaneous imaginings-like having guided imaginings-does not entail that the content of those imaginings is i-true. Indeed, the attitude of belief-like imagining in general is characterized by this lack of any 
power to render its content i-true. In imagining, we are aware that the imagined proposition is assessable for truth in the project's i-world, and not necessarily i-true, just as in believing a proposition, we are aware that the believed proposition is assessable for truth (that is, in the real world), and not necessarily true. Indeed, if we invoke only a project's imaginings, we cannot infer from them alone which propositions are i-true, which are i-false, and which are indeterminate. The mere fact that a proposition is imagined says nothing about whether it is i-true or not.

Since i-truths are not determined by imagining alone, to discover which i-truths have been set down in a spontaneous project we must consider a different mental act or state. I discuss this issue in the next section.

\subsection{Determination of Imaginary Truths}

To the extent that an imaginative project encompasses specific i-truths, the determination of those i-truths is not identical with belief-like imagining, but takes place in addition to belief-like imagining. That is, to the extent that an imaginative project involves specific i-truths, since imagining a proposition to be i-true, in itself, does not render that proposition i-true, there must be an additional mental act or state that is part of that project, part of the overall mental activity we engage in when we imagine-an act or state whose role is to posit propositions to be i-true. Of course, this mental act or state can also be called imagining; indeed, it can hardly be denied that the term imagining is used to denote different kinds of mental states in different contexts. Specifically, when we say, for example, 'imagine a world in which $p$ is true', we refer not, or not only, to belief-like imagining, but also to positing an $\mathrm{i}$-world in which $p$ is true. (In this vein, Manuel García-Carpintero (20I9: 27I), for example, distinguishes between 'ancillary imaginings' and 'constitutive imagining'; this distinction seems to correspond to my own, though García-Carpintero's focus, unlike mine, is not belief-like imagining, and his theory applies only to imagining in the context of engaging with fiction). In short, due to its functional role, the mental act or state of determining i-truths should be distinguished from belief-like imagining, as per the foregoing arguments. To distinguish this act or state from belief-like imagining, I refer to it simply as the determination of $i$-truths (the positing of $i$-truths, the setting down of $i$-truths, and so on).

In guided imaginative projects, i-truths are determined by the imaginer's compliance with the relevant instructions or intentions. There are various ways to ascertain which propositions are mandated (for example, by a work of fiction) to be i-true (see, for example, Walton I990: ch. 4; Currie I990: ch. 2; Davies 2007: ch. 4), various ways to follow rules governing the stipulation of i-truths, various ways to figure out which propositions we must posit to be i-true in order to learn from imagining (see, for example, Kind 2018), and so on. I do not discuss these ways here. However we recognize the propositions that are mandated to be i-true in our guided projects, we determine them to be i-true, as part of our imaginative project, upon grasping that mandate.

Obviously, in unguided projects, the determination of i-truths is not a response to any mandate or intention. This issue has been overlooked in the literature, apart 
from Walton (I990; 20I 5: ch. 2). Walton (I990: 44-45) argues that spontaneously imagining a proposition makes that proposition i-true (or as Walton puts it, fictionally true) by 'establishing a prescription' (45) to imagine it. This claim of Walton follows from his definition of 'fictionality' or 'fictional truths' (I990: 3543). Walton argues that a proposition is fictionally true if and only if it is 'to be imagined' (I990: 39). And since spontaneous imaginings do not arise in response to any external mandate, Walton maintains that the state of imagining itself establishes the prescription that its content is to be imagined, and thus it renders the imagined proposition fictionally true (or, on the current definition, i-true).

This explanation, however, raises several problems, some of which are pointed out by Walton himself, when he acknowledges that his initial 'reductive account' (2015: I7), namely that a proposition is fictionally true just in case there is a prescription to the effect that it is to be imagined, was unsatisfactory (2015: ch. 2). In my opinion, the main problem with Walton's account is that, as I showed, we do not always imagine i-truths. Contra Walton (I990), imaginings, in themselves, do not render their content i-true and cannot be used to define i-truths (see also Chasid 2020: 33-34; 40-42).

Walton (2OI 5:28) suggests a different explanation, which is not committed to his initial reductive account of how fictional truths are determined: in spontaneous imaginative projects, the determining of i-truths is a matter of a decision on the part of the imaginer. But this proposal is also problematic. If Walton means that the decision is made in reflecting on the project retrospectively, this claim is incorrect. For to the extent that an imaginative project involves i-truths, we are not free to decide, post-project, which i-truths it involved, given that the project has ended. Rather, we can discover these i-truths by retrospective reflection, just as we discover which propositions were imagined in the project, how it unfolded, and so on. And if Walton means that the decision is made during the imaginative project, his claim is inconsistent with the fact that the overall manner in which the project arises is spontaneous, that is, not deliberately scripted.

Of course, since Walton mentions this claim only briefly, it is possible that he is not using the term decide in the strict philosophical sense that implies agency or deliberate action. That is, Walton might be using decide to refer to the fact that in spontaneous projects, we simply determine i-truths-albeit non-deliberately (indeed, much as we imagine propositions non-deliberately). On this interpretation of Walton's claim, that is, that in spontaneous imaginative projects, the determining of $\mathrm{i}$-truths is a matter of a non-deliberate decision on the part of the imaginer, the following explanation can be seen as an explication of his claim.

On this explanation (call it explanation A), in unguided projects, just as we imagine certain propositions spontaneously, so we establish the relevant i-world spontaneously. That is, the act of determining i-truths, being part of an extemporaneous mental activity, namely, the imaginative project in question, is carried out extemporaneously. The idea is that, if an imaginative project can unfold unintentionally vis-à-vis the imaginings it encompasses, it can also unfold unintentionally vis-à-vis the determination of i-truths. For instance, in spontaneously imagining that there is a gold nugget on the riverbed, and then that the changed illumination-the setting sun-reveals that the previously shiny object 
is just a pebble, we also (that is, in addition to imagining) extemporaneously establish an i-world in which it is true that the object is not gold, but a pebble.

Explanation A does not distinguish between unguided projects and guided projects vis-à-vis the extent to which they involve specific i-truths. With respect to the determination of i-truths, the only difference between unguided and guided projects pertains to the spontaneity of the state or act of determination. Of course, since unguided projects do not arise in response to directives, discovering the i-truths they involve might not be easy. Again, although we are susceptible to being confused about our own stream of experience (Schwitzgebel 20II), it does not follow that we always err. Despite the fact that unguided projects arise without the mediation of beliefs as to how they should evolve, the imaginer can accurately report, upon retrospective reflection, on whether what she imagined was also posited to be i-true-just as she can accurately report that she imagined certain propositions, reacted to her imaginings in such-and-such a way, and so on. In the gold nugget case, for instance, the imaginer is likely to report that the proposition she first imagined-that is, that there was a gold nugget in the river-was determined, probably at the second stage of the project, to be i-false.

However, explanation A seems problematic in a certain respect. Whatever the extent to which we are susceptible to error in describing our spontaneous projects, the access we have to our imaginings, our reactions to those imaginings, and other mental elements of such imaginative projects is significantly more straightforward than the access we have to the (alleged) act or state of determining i-truths. The difficulty of pinpointing this act or state in spontaneous projects, where it does not ensue in response to intentions, rules, and the like invites the suspicion that in these projects, it simply does not exist. Consider the gold nugget project. It does not seem difficult to pinpoint the imaginings that this project involved, the shift from imagining a gold nugget to imagining a pebble, our reaction to this shift, and so on; discerning these elements of the project is quite straightforward. By contrast, discerning the act of determining i-truths, and ascertaining the stage at which it was made, is far from straightforward. In trying to discover whether a specific proposition was i-true, we generally do not directly recall the act of making a determination to that effect; rather, we recall how our imaginings evolved, and from this recollection try to infer which i-truths were spontaneously posited. For instance, we recall that, after imagining the gold nugget, we imagined that the changed illumination revealed that the object was only a pebble; relying on the way our imaginings evolved, we reason that the later imaginings were correct, not the initial ones. We likewise conclude that the act or acts of determining these i-truths took place, more or less, when we engaged with the later, revised imaginings.

But this reasoning is flawed. For one thing, why must we conclude that, since there was a shift from imagining one proposition to imagining a contrary one, the later imagining (that is, that the change in illumination revealed that the object was only a pebble) was the correct one? In general, there is no reason to assume, without further qualification, that the later imagining, or the imagining that revises previous imaginings (within the project), has i-true content. Likewise, there is no reason to assume that the determination of $\mathrm{i}$-truths occurs, roughly, when 
the initial imagining is revised. Given that imaginings do not render their content i-true, the fact that while imagining, we experienced the revelation that the object on the riverbed was only a pebble says nothing about whether this content was also determined to be i-true. Since spontaneous projects are not framed by intentions - and specifically, not by the intention to imagine the i-truth-the way in which imaginings evolve in such a project says little, if anything about which i-truths (if any) were determined. With respect to the act of determining specific i-truths, spontaneous imaginings evolve in a contingent manner.

Note also that, since spontaneous projects also end spontaneously, we can likewise speculate about what would happen were our project to continue (spontaneously) and proceed to another shift, namely, a shift to imagining that the object on the riverbed is a gold nugget after all. If, to discover which i-truths were posited, we rely on how our imaginings have (spontaneously) evolved, this speculation about an additional-that is, a second-shift might undermine our initial judgment that it was i-true that the object was a pebble. It might, perhaps, be claimed that such an extended project would differ from our original project with regard to the $\mathrm{i}$-truths the projects comprise. But there is no reason to say that they necessarily differ in this respect. Although the original (one-shift) and the conjectured (two-shift) projects comprise different imaginings, it need not mean that they comprise different i-truths. Such a speculation about an extended project can easily undermine our initial judgment about which i-truths our spontaneous project involved. (Note that, in principle, i-truths can be determined even after a project is paused and then continues. This scenario can occur even in 'paused' guided projects, for example, projects that arise in response to serial fictions such as the Star Wars films; see Lee Walters's [20I7] analysis.)

Moreover, even if we can correctly conclude, by some indirect means, that our project encompassed certain i-truths, discovering at which stage of the project these i-truths were determined is far from straightforward. In the gold-nugget project, for example, it might at first seem that if it is i-true that the object is only a pebble, this i-truth was determined, roughly speaking, when we shifted from imagining that it was gold to imagining that it was a pebble. Suppose, however, that we realize that our project echoed a recent real-world experience, say, a recent trip to a gold-panning site in Colorado, during which we observed that pebbles illuminated by the sun can be readily mistaken for gold nuggets. Recalling this experience might undermine our judgment about when the i-truth that the object was just a pebble was determined. For if the project was (spontaneously) structured to reflect our real-world experience, the i-truth that the object on the riverbed was a pebble seems to have been determined right at the outset of the project.

I adduce these complications that arise in trying to pin down what a given project's i-truths are, and when they are set down, not, or not only, to show that this undertaking is susceptible to error. In fact, if explanation A is correct, it can explain this susceptibility. In general, absent evidence to the contrary, imaginers tend to think that what they imagine at a certain stage is i-true. Though I will not develop this argument here, it seems that since spontaneous projects are not constrained by explicit criteria for i-truth (intentions, instructions, rules, and the 
like), having imagined a proposition to be true can easily induce the imaginer, in reflecting on her project, to conclude that this proposition was also determined to be i-true. Compare imaginings to beliefs: much as we do not distinguish, from the first-person perspective, between true propositions and propositions we believe to be true (although we know they can, and sometimes do, differ), we do not generally distinguish, at any given stage of an imaginative project, between i-truths and propositions we imagine to be true.

This argument merits a separate discussion, but if it is sound, explanation A can invoke it in explaining the difficulty we encounter in seeking to discern the act of determining i-truths. However, this difficulty might also indicate that the attempt to pinpoint such determinations is futile, since there might not be any such determinations. That is, explaining the difficulty in ascertaining what a spontaneous imaginative project's i-truths are presupposes that such projects involve determinations of i-truths. But precisely because it is difficult to discern such determinations, we might well conclude that such (alleged) acts are not part of spontaneous projects. Spontaneous projects, it might be suggested, can be fully accounted for without assuming that they involve determinations of specific i-truths. The difficulty of discerning acts of determining i-truths-a difficulty that does not arise with respect to other elements of spontaneous imaginative projects (that is, imaginings, our reactions to them, and the like)-is sufficient motivation to consider an alternative explanation.

\subsection{No Imaginary Truths?}

On a different explanation, explanation $\mathrm{B}$, there is a radical difference between guided and unguided projects: whereas in guided projects we determine specific i-truths by complying with external criteria (such as a fictional work's assumptions, rules), or in line with intentions, in unguided projects we do not determine any specific i-truths. This does not mean that spontaneous imaginings are not directed at an i-world, only that the i-world is indeterminate. In the examples of the soon-to-explode building and gold nugget, we shift from imagining one proposition to imagining an incompatible proposition, while being aware that our imaginings are putatively assessed for truth in the same i-world. The crucial point is that, given the absence of guidance as to what is true, this i-world is indeterminate: we imagine certain propositions to be true, but whether these propositions are true in the $\mathrm{i}$-world is undetermined.

Explanation B is consistent with the thesis defended in section I, namely, that belief-like imaginings do not render their content i-true. For this thesis does not entail that specific i-truths must obtain, but argues that if i-truths obtain, they are not determined by our belief-like imaginings. Explanation B is also compatible with the arguments adduced in section I. The unfolding of spontaneous projects does not require the determination of specific i-truths, it requires only awareness that the imagined content is putatively assessed for truth in the project's i-world. In particular, directing our imaginings at that i-world suffices to account for our emotional, cognitive, and conative reactions to our imaginings. Again, compare imaginings to beliefs. To account for feelings of discovery, surprise, relief, and the 
like, as well as desires and other conative states, we need only invoke the subject's beliefs, not whether they are true or false. Whatever the real world is like, our feelings, desires, and the like, depend only on what we believe it to be like. Similarly, to explain our imaginative mental activity, all we need assume is that we imagine certain propositions to be true, not that specific propositions are true in our project's i-world. In the gold nugget project, for instance, it is not determined whether the shiny object is a nugget or a pebble. The imaginer takes the imagined propositions to be putatively assessed for truth in that i-world, and her reactions arise-so explanation B contends-only because she shifts from imagining one proposition to imagining another.

On explanation $\mathrm{B}$, if the imaginer reports that specific i-truths obtained in her project-for example, that it was i-true that the shiny object was not gold-she must be mistaken. This generalization seems problematic, but in light of the aforementioned tendency to misdescribe our spontaneous mental activities, it can be deemed a relatively minor problem. Given B's theoretical parsimony, the price that explanation B exacts in this respect is tolerable. Note further that on explanation $\mathrm{B}$, the determination of specific i-truths plays no intrinsic role in imaginative projects in general. That is, the core imaginative mental activity-the mental activity common to guided and unguided projects-need not involve specific i-truths. The sole context in which specific i-truths are posited is that of guided projects, where specific truths are stipulated so as to convey instructions about what is to be imagined (for example, if $p$ is presented as i-true by a work of fiction, the imaginer will typically respond by imagining that $p$ ).

At first sight, explanation $\mathrm{B}$, being more parsimonious than explanation $\mathrm{A}$, might seem more theoretically appealing. However, in addition to its problematic implication that vis-à-vis unguided projects, an imaginer's reports about specific i-truths must be mistaken, explanation B has another shortcoming. For specific $\mathrm{i}$-truths do play a significant role in unguided imagining. In some cases, differences between spontaneous imaginative projects can best be accounted for by invoking differences between their respective i-truths. If spontaneous projects sometimes differ as to the i-truths set down in them, it follows that such projects indeed involve specific i-truths.

To see this more clearly, consider Mary, who finds herself imagining that she is interviewing Lady Gaga, winner of the 2019 Academy Award for Best Actress (This example is based on a similar example in Williams [I973: 29].) Mary's imagining can be part of two different imaginative projects. To establish the difference, suppose that, after Mary tells her spouse about her daydream, her spouse replies that, although Lady Gaga was nominated, Olivia Colman won the award.

At this stage, two different scenarios could unfold. On the first scenario, Mary reacts to her spouse's comment with embarrassment, admitting that she had falsely believed that Lady Gaga, not Olivia Coleman, had won, and hence had imagined that she was interviewing Lady Gaga. That is, Mary admits that her daydream went wrong (so to speak) in the sense that, had she known who the real winner was, her daydream would have been about that person: she would have imagined interviewing Olivia Coleman, not Lady Gaga. 
On the second scenario, Mary dismisses her spouse's comment, saying that she knows, or does not care, that Olivia Coleman won. Her daydream, she claims, reflected the (non-actualized) possibility that Lady Gage won: she imagined that, regardless of the real-world winner, she was interviewing Lady Gaga qua winner.

The two projects differ in structure. Yet the difference is not between the imagined propositions, for in both projects, Mary imagines precisely the same proposition, namely, that she is interviewing Lady Gaga, 2019 winner of Best Actress. Nor does the difference pertain to Mary's intentions, since both projects arise spontaneously. Rather, each project sets down (spontaneously) as i-true a different proposition about the interviewee's identity. In the first project, the i-world winner is posited to be whoever the real-world winner is (that is, Olivia Coleman); in the second project, the i-world winner is posited to be Lady Gaga, regardless of the real-world winner. Mary's failure in the first project follows from a mismatch between what was fixed as true in the i-world regarding the putative object of Mary's imagining, and what Mary actually imagined. In the second project, no such mismatch occurred, since Mary's imagining accorded with what was set down as obtaining in the i-world: Lady Gaga was posited as the putative object of Mary's imagining, and Mary indeed imagined interviewing Lady Gaga. (Note that it is not the case that the interviewee in the first project was posited to be the person Mary believed to be the real-world winner. Were it the case, there would have been no failure, since Mary indeed imagined the person she believed to be the real-world winner-that is, Lady Gaga.)

The idea is that in addition to differing with respect to the imagined propositions, spontaneous imaginative projects can also differ in the extent to which their respective i-worlds are set down as being similar to the real world, that is, differ as to which truths simpliciter are set down as the project's i-truths. It follows that, contra explanation $\mathrm{B}$, spontaneous projects can involve the determination of specific i-truths.

Supporters of explanation B might seek to argue that, although the difference between Mary's two projects is a difference in what her imaginings are structured as being about, this structural difference does not entail that different $i$-truths obtain in the two projects (and hence, does not entail that the projects set down specific i-truths). Perhaps imaginative projects could, B's supporters might suggest, involve some sort of ad hoc mechanism for determining the extent to which a specific imagining is about real-world objects. In Mary's first project, the mismatch is indeed between what Mary imagined and what her imagining was structured as being about. But the determination as to whether her imagining is supposed to be about the real-world winner or about Lady Gaga is an ad hoc determination that does not involve any i-truths. Note that the crucial element of this hypothetical claim is not that imaginings with the same content can be about different real-world objects or events; rather, it is the assertion that the determination of what an imagining is about does not depend on what the pertinent i-world is like. According to this hypothetical claim, although imaginings are directed at the pertinent $\mathrm{i}$-world (in the sense that their content is putatively assessed for truth in that world), what they are about can sometimes be detached from the i-world, and extemporaneously determined to be about a 
real-world object or event that is not part of the i-world. Thus, on this claim, the only difference between Mary's two projects is that in the first project, her imagining is structured, ad hoc, such that it is about the real-world winner, whereas in the second, it is structured, ad hoc, such that it is about Lady Gaga, though the $\mathrm{i}$-worlds of the two projects are fully indeterminate.

(Note that various versions of the claim that imaginings can be about real-world objects or events have been suggested. Interestingly, a version of this claim is put forward by Davies [2015]; see also Friend [2000] regarding fictive utterances. Davies argues that authors of fictions can intend that readers imagine certain things about what the author takes to be a 'real setting' [Davies 2015: 44, emphasis Davies's], in which case they are asked to believe something about that 'real setting'. Yet as Davies presents his claim, the real setting is obviously part of what is 'true in the story' [45] Davies's notion of 'true in the story' overlaps the Waltonian notion of 'true in the i-world' that I invoke in this article, a notion that is also applicable to spontaneous projects; see above, the introduction. By contrast, on the hypothetical claim in question, imaginings can, by some ad hoc mechanism, be imaginings of real settings, without those settings being part of the i-world.)

I certainly grant that, in addition to imaginings, imaginative projects can involve other structural features. But it is implausible to invoke ad hoc features to explain a difference if a more obvious explanation is at hand. Without further qualification, when the i-world is set down as being the same as the real world in specified respects, specific i-truths must be set down, and this is where imaginative projects can fail, so to speak, as happened in the case of Mary's first project. Explanation $\mathrm{B}$, in explaining the difference between Mary's two projects by invoking an ad hoc mechanism that somehow establishes the structure of those projects without recourse to the notions of i-truth and i-falsehood, loses its purported advantage, namely, parsimony.

We can therefore conclude that unguided projects sometimes involve specific i-truths: explanation B's claim that in unguided projects no i-truths are determined is highly implausible. Of course, i-truths might not be set down in unguided projects as often as they are set down in guided projects. The extent to which unguided projects do involve i-truths can be ascertained, if not by relying on imaginers' reports, by the strategy I have suggested, namely, showing that differences between imaginative projects can be best explained by taking them to be differences between specific i-truths.

\section{Conclusion}

Belief-like imaginings rarely arise unaccompanied. I have shown that, in addition to the mental states that accompany them (such as emotional and conative reactions, mental imagery, motivations), they are also often accompanied by the mental state or act of determining i-truths.

I opened by asserting that imagining a proposition in a belief-like way does not render that proposition i-true. Showing that imaginative projects often involve i-truths, it argued that in addition to imaginings, the determination of i-truth is 
part of such projects. Although this claim can be readily demonstrated with regard to guided imaginative projects - that is, projects that are intended or arise in response to instructions-it is more difficult to see that spontaneous projects also involve the determination of $\mathrm{i}$-truths, though the act of determining an i-truth is impromptu.

Examining competing explanations regarding whether-and if so, how-specific $\mathrm{i}$-truths are set down in spontaneous projects, I showed that comparing similar imaginative projects is an effective strategy for discovering whether such projects set down specific i-truths. Given the problematic nature of our access to our mental life (and, in particular, our imaginative excursions), this strategy might be more useful than relying on imaginers' reports about which propositions, if any, were set down as i-true in their imaginative projects.

ALON CHASID

BAR-ILAN UNIVERSITY alon.chasid@gmail.com

\section{References}

Chasid, Alon. (2020) 'Imagining in Response to Fiction: Unpacking the Infrastructure'. Philosophical Explorations, 23, 3 I-48.

Chasid, Alon. (forthcoming) 'Belief-like Imagining and Correctness'. American Philosophical Quarterly.

Currie, Gregory. (I990) The Nature of Fiction. New York: Cambridge University Press.

Currie, Gregory, and Ian Ravenscroft. (2002) Recreative Minds: Imagination in Philosophy and Psychology. Oxford: Oxford University Press.

Davies, David. (2007) Aesthetics and Literature. London: Continuum.

Davies, David. (2015) 'Fictive Utterance and the Fictionality of Narratives and Works'. British Journal of Aesthetics, 55, 39-55.

Doggett, Tyler, and Andy Egan. (2012) 'How We Feel about Terrible, Non-existent Mafiosi'. Philosophy and Phenomenological Research, 84, 277-306.

Friend, Stacie. (2000) 'Real People in Unreal Contexts, or Is There a Spy among Us?' In Anthony Everett and Thomas Hofweber (eds.), Empty Names, Fiction and the Puzzles of Non-existence (Stanford: CSLI), I $83_{3}-203$.

García-Carpintero, Manuel. (2019) 'Normative Fiction-Making and the World of the Fiction'. Journal of Aesthetics and Art Criticism, 77, 267-79.

Gendler, Tamar Szabó. (2003) 'On the Relation between Pretense and Belief'. In Matthew Kieran and Dominic McIver Lopes (eds.), Imagination, Philosophy, and the Arts (London: Routledge), I254I.

Ichino, Anna. (2019) 'Imagination and Belief in Action'. Philosophia, 47, I 5 I7-534.

Kind, Amy. (2013) 'The Heterogeneity of the Imagination'. Erkenntnis, 78, I4 I-59.

Kind, Amy. (2016) 'Introduction: Exploring Imagination'. In Amy Kind (ed.), The Routledge Handbook of Philosophy of Imagination (New York: Routledge), I-I I.

Kind, Amy. (2018) 'How Imagination Give Rise to Knowledge'. In Fiona Macpherson and Fabian Dorsch (eds.), Perceptual Imagination and Perceptual Memory (Oxford: Oxford University Press), 227-46.

Langland-Hassan, Peter. (2012) 'Pretense, Imagination, and Belief: The Single Attitude Theory'. Philosophical Studies, I 59, I $55-79$.

Liao, Shen-yi, and Tyler Doggett. (20I4) 'The Imagination Box'. Journal of Philosophy, I I I, 25975 .

Liao, Shen-yi, and Tamar Szabó Gendler. (2019) 'Imagination'. In Edward N. Zalta (ed.), Stanford Encyclopedia of Philosophy. https://plato.stanford.edu/archives/winzorg/entries/imagination/. 
Nichols, Shaun. (2004) 'Imagining and Believing: The Promise of a Single Code'. Journal of Aesthetics and Art Criticism, 62, I29-39.

Nichols, Shaun, and Stephen P. Stich. (2003) Mindreading: An Integrated Account of Pretence, Self-Awareness, and Understanding of Other Minds. Oxford: Oxford University Press.

Schellenberg, Susanna. (2013) 'Belief and Desire in Imagination and Immersion'. Journal of Philosophy, I Iо, 497-517.

Schwitzgebel, Eric. (20I I) Perplexities of Consciousness. Cambridge, MA: MIT Press.

Walters, Lee. (2017) 'Fictionality and Imagination, Revisited'. Journal of Aesthetics and Art Criticism, 75, I 5-2I.

Walton, Kendall L. (I990) Mimesis as Make-Believe: On the Foundations of the Representational Arts. Cambridge, MA: Harvard University Press.

Walton, Kendall L. (2015) In Other Shoes: Music, Metaphor, Empathy, Existence. New York: Oxford University Press.

Williams, Bernard. (1973) 'Imagination and the Self'. In Problems of the Self: Philosophical Papers, 1956-1972 (Cambridge: Cambridge University Press), 26-45. 